\title{
Energetic cost of reduced foraging under predation threat in newly hatched ocean pout
}

\author{
Shaun S. Killen*, Joseph A. Brown \\ Department of Biology/Ocean Sciences Centre, Memorial University of Newfoundland, St. John's, \\ Newfoundland A1C 5S7, Canada
}

\begin{abstract}
Previous research has shown that young fishes will decrease foraging activity while in the presence of a predatory threat. In most of these studies, however, individuals have been exposed to acute pulses of predatory threat of short duration; thus, little is known about the long-term impacts of predatory threat on development in newly hatched fish. In the present study, newly hatched ocean pout Macrozoarces americanus were visually exposed to predatory juvenile Atlantic cod Gadus morhua for $6 \mathrm{~h}$ per day during the feeding period. At $3^{\circ} \mathrm{C}, 8 \mathrm{wk}$ old pout not exposed to predators were significantly larger (standard length and wet mass), and had a higher hepatosomatic index than fish exposed to predators. Pout exposed to predators also had lower levels of whole-body phospholipids and triacylglycerol, as well as decreased levels of essential fatty acids (arachidonic acid and eicosapentaenoic acid). Interestingly, there were no differences in size, hepatosomatic index or lipid content between the 2 treatments when the experiment was performed at $8^{\circ} \mathrm{C}$, despite a decrease in foraging activity of the pout exposed to predators at this temperature. These results suggest that frequent predatory threat can affect the development of newly hatched fishes, and that temperature can affect the ability to observe growth trade-offs when performing threat-sensitive foraging experiments with ectotherms.
\end{abstract}

KEY WORDS: Predation · Foraging · Trade-offs · Lipids · Growth · Behavior · Ocean pout - Resale or republication not permitted without written consent of the publisher

\section{INTRODUCTION}

Consumption by predators is a major source of mortality in fish populations, especially during the early life stages (Bailey \& Houde 1989). However, predators can also influence prey behavior. For example, in the presence of predators, prey individuals will often reduce foraging activity in exchange for predator avoidance behaviors (e.g. hiding, freezing; Lima \& Dill 1990, Houston et al. 1993, Lima 1998a,b). This concept is known as 'threat-sensitive' foraging (Helfman 1989). By reducing foraging activity, prey become less obvious to predators and may be more vigilant toward potential attacks.

It is widely assumed that threat-sensitive foraging comes at the cost of reduced energy intake (Abrahams \& Dill 1989, Fuiman \& Magurran 1994, Lima 1998a,b). Indeed, energy is often used as a common 'currency' for evaluating lost foraging opportunities in foraging models or experiments examining foraging behavior. In support of this assumption, individuals are less likely to engage in threat-sensitive foraging if they are hungry or have increased energetic demands (Dill \& Frazer 1984, Godin \& Crossman 1994, Lima 1998a,b). However, there has been little attempt to quantify the actual energetic cost of threat-sensitive foraging, or the long-term effects of frequent interruptions to regular foraging behavior. From the few studies that have been performed in this area, it is known that the costs of reduced foraging may accumulate over time and cause reduced growth in individuals that are frequently exposed to predation threat (amphibians Skelly 1992, Werner \& Anholt 1996, Peacor \& Werner 2000; aquatic insect larvae-Dixon \& Baker 1988, Ball $\&$ Baker 1996). Aside from the analysis of growth rates, however, the effects of threat-sensitive foraging on other aspects of energy acquisition and nutrition are largely unexplored. 
For fishes, most studies examining the effects of predatory presence on growth rates have been concerned with predator-induced shifts by prey species to energy poor habitats (e.g. Fraser \& Gilliam 1992, Tonn et al. 1992, Diehl \& Eklov 1995, Perrson \& Eklov 1995). For this reason, the long-term effects of threat-sensitive foraging on reduced growth and energy storage in fishes remains unknown. Furthermore, among those studies of predator-induced habitat shifts, the focus is usually on juvenile or adult individuals. However, reduced growth may be especially significant for newly hatched fishes, since this is a delicate life-stage in which rapid growth and development is extremely important (Bailey \& Houde 1989, Fuiman 1994, Fuiman \& Magurran 1994, Leggett \& Deblois 1994). Individuals that grow slowly will be at a disadvantage because they will spend more time as a potential food source for predators (Fuiman \& Magurran 1994). It is known that very young individuals, and even larval fishes, will respond to predators and forage in a threat-sensitive manner (Williams \& Brown 1991, Bishop \& Brown 1992, Skajaa et al. 2003). Currently, the only studies examining threat-sensitive foraging in newly hatched or larval fishes have involved exposing the prey individuals to acute pulses of predatory threat lasting a very short duration (Williams \& Brown 1991, Bishop \& Brown 1992, Skajaa et al. 2003, Engstrom-Ost \& Lehtiniemi 2004). For these reasons, the long-term effects of frequent threat-sensitive foraging on the growth and survival of young fishes are not known.

To evaluate the long-term fitness consequences of reduced foraging under predation threat, we reared newly hatched ocean pout Macrozoarces americanus with and without the presence of frequent predatory threat. It was hypothesized that frequent interruptions to regular foraging behavior in the presence of predators would negatively affect the growth of the young fish. Furthermore, it was thought that reduced energy intake due to a reduction in foraging activity would have consequences for the lipid composition of the prey individuals, since lipids are an important metabolic fuel in young fishes (Sargent 1995). We also performed the experiments at 3 and $8^{\circ} \mathrm{C}$ to investigate how water temperature affects the extent of the trade-off between foraging and predator avoidance, and the cost of reduced foraging opportunities. It was expected that, due to increased energetic demands, pout acclimated to the higher temperature would be more motivated to forage under the threat of predation, and would therefore show a less drastic cost associated with reduced growth rates.

\section{MATERIALS AND METHODS}

Eggs of ocean pout Macrozoarces americanus were collected by SCUBA and transported to the laboratory and placed in incubators supplied with aeration and flowing seawater at ambient temperatures. Following hatching (in early January), approximately half of the ocean pout were gradually acclimated to $8^{\circ} \mathrm{C}$ over the course of $1 \mathrm{wk}$, while the rest were allowed to remain at ambient temperatures $\left(3^{\circ} \mathrm{C}\right)$. After this acclimation period, arbitrarily selected groups of pout were transferred into eight experimental tanks (mean wet mass $\pm \mathrm{SE}: 3^{\circ} \mathrm{C}=270.4 \pm 6.47 \mathrm{mg}, 8^{\circ} \mathrm{C}=278.1 \pm 5.32 \mathrm{mg}[\mathrm{no}$ significant difference between temperatures; unpaired $t$-test, $\mathrm{p}=0.395]$; mean standard length $\pm \mathrm{SE}: 3^{\circ} \mathrm{C}=$ $42.41 \pm 0.17 \mathrm{~mm}, 8^{\circ} \mathrm{C}=43.49 \pm 0.20 \mathrm{~mm}$ [significant difference; unpaired $t$-test, $\mathrm{p}=0.002]$. All fish were of the same age at the start of the experiment. Half of the tanks were maintained at $8^{\circ} \mathrm{C}$ while the rest were kept at $3^{\circ} \mathrm{C}$ (the predator and control treatments within each temperature regime are described below). At the time of this study, the ambient water temperature was $3^{\circ} \mathrm{C}$, but inshore water temperatures off Newfoundland can reach as high as $8^{\circ} \mathrm{C}$ in the late-spring and summer, when ocean pout similar to the sizes used in this study may still be found in the wild (in contrast to the pelagic larvae of many marine fishes that do not exist over a wide temperature range).

The experimental tanks were $40 \mathrm{l}$ flow-through aquaria which were divided into 2 separate chambers - a 'predator' chamber measuring $14 \times 26 \times$ $30 \mathrm{~cm}$ (length $\times$ width $\times$ heigth), and a 'prey' chamber measuring $36 \times 26 \times 30 \mathrm{~cm}$ (Fig. 1). The chambers were separated by 2 adjacent partitions, one transparent and non-removable and the other removable and

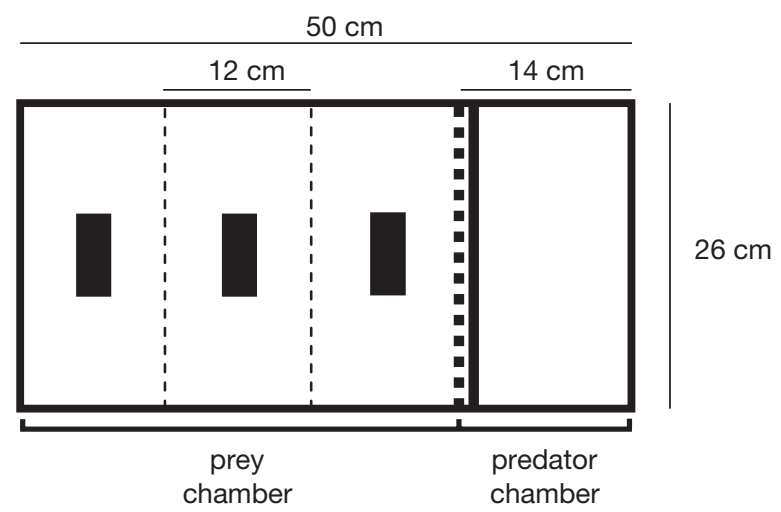

Fig. 1. Example of a $40 \mathrm{l}$ experimental tank (top view), showing locations of prey chamber $(36 \times 26 \times 30 \mathrm{~cm}$ : length, width, height), containing 25 newly hatched ocean pout Macrozoarces americanus), and the predator chamber $(14 \times 26 \times$ $30 \mathrm{~cm}$ : containing 2 juvenile Atlantic cod Gadus morhua in predator treatment but empty in control treatment). Heavy dashed line represents permanent transparent partition; heavy continuous line represents removable opaque partition. Light dashed lines represent grid sections within prey chamber (used to quantify proximity of pout to predator chamber). Each grid section contains a small section of PVC pipe for cover (filled rectangles). See 'Materials and methods' for experimental protocol 
opaque. These partitions allowed visual exposure of the pout to the predators by raising the opaque partition, while preventing physical contact between the predators and larvae. Water flowed continuously into each tank, starting at the prey chamber, passing through a small opening into the predator chamber, and then out of the tank (the direction of flow was toward the predators). For this reason we believe the effects of olfactory cues originating from the predator were minimal. In each tank, the prey chamber contained 25 ocean pout. We randomly assigned 2 tanks at each temperature to contain 2 predatory juvenile cod Gadus morhua (mean total length $13.76 \pm$ $0.36 \mathrm{~cm}$ ) in the predator chamber. The remaining tanks were the control treatment and contained ocean pout but no predators. Previous work has shown that the threat-sensitive behavior of young fishes can be dependent on the distance from the predator, due to limitations in sensory capabilities (Bishop \& Brown 1992). To analyze prey behavior in relation to proximity to the predators, and to ensure that equal numbers of behavioral observations were made for all tank locations, the prey chamber was further divided into 3 grid sections using markings on the outside of the tanks. In addition, each grid section contained a small section of PVC pipe that could potentially be used for cover by the ocean pout. This was done to reduce any stress response elicited by observing the predators, and because individuals in the wild would be likely to have the opportunity to hide while under predation threat. All experimental tanks were exposed to a 16:8 h light:dark photoperiod.

Ocean pout in all treatments were fed daily by adding live enriched Artemia sp. nauplii to each tank 4 times per day to maintain prey densities at approximately 1000 Artemia sp. $\mathrm{l}^{-1}$. The Artemia sp. were observed to be actively swimming in the water column at all times of the day (at each temperature), and were mixed in the water column with the aid of a small airstone placed into each tank. Any excess prey and fecal matter at the bottom of the tanks were removed by siphoning at the end of each day.

Behavioral observations. Each day, pout in the predator treatments were visually exposed to the predatory cod for $6 \mathrm{~h}$ by removing the opaque partition. The control tanks also had the opaque partition removed during this time, but the pout were not exposed to predators. Behavioral observations of foraging and predator avoidance were performed 3 times a week beginning after the fishes were transfered to the experimental aquaria. Following removal of the opaque partition, Artemia sp. were added the prey chamber of the tanks. After a 2 min acclimation period, the focal animal technique (Altmann 1974) was used to observe the behavior of the ocean pout. Using this technique, the behavior of 1 individual is recorded over a specific length of time (1 min in the present study). Different behaviors were recorded and tabulated using a hand-held Psion event recorder and associated software (The Observer 3.0, Noldus Information Technology). The behavioral repertoire of the ocean pout included 3 easily observable modal action patterns (MAPs; Barlow 1968). These were 'crawl', 'orient', and 'lunge' (Table 1).

During each observational period, behavioral observations were conducted on 4 pout in each grid section of the prey chamber, with 2 pout that were in the open and 2 pout that were hiding under cover (for a total of 12 observations per tank). Differences were found in the foraging activity and response to predatory exposure among pout that were hiding and pout that were in the open, but for this study, behavioral observations were only analyzed if the pout were judged to be able to observe the predatory chamber. Over the course of a given observation, it was common for individual pout to switch between being in the open and hiding, or to change grid sections within the tanks (this was more common at $8^{\circ} \mathrm{C}$ due to the increased activity of individuals at this temperature). In these cases, observations were divided into time intervals representing the time spent in each location. The frequencies of the observed behaviors were then converted to counts $\mathrm{min}^{-1}$. To avoid biases caused by disproportionate counts of behaviors while in a location for a short amount of time, intervals were not included in the final analysis if the focal pout spent less than $5 \mathrm{~s}$ in that location.

Growth measurements. At the beginning of the experiment and at the end of each week, 5 ocean pout were randomly selected from each tank and anaesthetized using MS-222 to be measured for standard length. Standard length measurements were made using Matrox Inspector 3.0 image analysis software on images captured using a digital camera (Pixera PVC 100C). Following image capture, the fish were allowed to recover from the anaesthesia and were returned to the appropriate tanks.

Table 1. Macrozoarces americanus. Description of modal action patterns (MAPs) observed for newly hatched ocean pout reared with and without frequent predatory exposure

\begin{tabular}{|ll}
\hline MAP & Description \\
\hline Crawl & $\begin{array}{l}\text { Short forward movement (less than 1 s in } \\
\text { duration) while remaining in contact with tank } \\
\text { bottom, being supported by pectoral fins }\end{array}$ \\
Orient & Turning of eyes, head or body toward prey item \\
Lunge & $\begin{array}{l}\text { Rapid forward motion toward prey item } \\
\text { Usually preceded by at least 1 'orient' }\end{array}$
\end{tabular}


At the beginning and end of the experiment, 7 fish from each tank were collected for the analysis of wet mass. Individual ocean pout were quickly dried with a paper towel, and then placed on dry, tared weighcontainers. Their mass was then measured using a microbalance. In addition, the individuals collected at the end of the experiment had their livers removed with the aid of a dissecting microscope. The livers were then weighed (using a microbalance), and expressed as a percent of total wet mass to obtain the hepatosomatic index (HSI) for each individual.

Lipid analysis. After the temperature acclimation period (and prior to the transfer of individuals into the experimental aquaria), randomly selected individuals were captured from their holding tanks at each temperature and immediately flash frozen in liquid nitrogen for later lipid analysis ( $\mathrm{n}=8$ for each temperature). At the end of the experiment, 5 pout from each tank $(n=10$ per treatment) were captured in an identical manner. These samples were then frozen at $-80^{\circ} \mathrm{C}$ for approximately 3 mo until the lipid analysis could be performed.

In preparation for lipid analysis, individual pout were thawed, quickly rinsed with distilled water, and carefully measured for wet weight using lipid clean instruments and weigh-foils. Lipid extraction was then performed using a variation of the Folch procedure (Folch et al. 1957) as described by Parrish (1998). Briefly, individual pout were homogenized in $7.5 \mathrm{ml}$ of 2:1 chloroform-methanol and washed with water to remove non-lipid contaminants. The entire lower organic phase was then collected and washed 4 times using 2:1 chloroform-methanol.

Quantitative determination of lipid classes was performed on these extracts with rod thin-layer chromatography with flame ionization detection (TLC/FID) with a MARK V Iatroscan (Iatron Laboratories). The extracts were spotted on silica gel coated chromarods and a 3-stage development system was used to separate lipid classes (described in detail by Copeman et al. 2002). After each separation, the rods were scanned and the 3 resulting chromatograms were combined using T-scan data scan software (RSS). The signal (detected in millivolts) was quantified using lipid standards (Sigma).

Fatty acid methyl esters (FAME) were prepared by transesterfication with $10 \% \mathrm{BF}_{3}$ in methanol at $85^{\circ} \mathrm{C}$ for $1 \mathrm{~h}$ (Morrison \& Smith 1964, Copeman et al. 2002). A Varian Model 3400 GC equipped with a Varian 8100 autosampler was used for qualitative fatty acid analysis (Varian). The column was an Omegawax 320 column, $30 \mathrm{~m}, 0.32 \mathrm{~mm}$ i.d., $0.25 \mu \mathrm{m}$ film thickness (Supelco). Hydrogen was used as the carrier gas and the flow rate was set at $2 \mathrm{ml} \mathrm{min}{ }^{-1}$. The column temperature profile was $65^{\circ} \mathrm{C}$ for $0.5 \mathrm{~min}$, hold at $195^{\circ} \mathrm{C}$ for $15 \mathrm{~min}$ after ramping at $40^{\circ} \mathrm{C} \mathrm{m^{-1 }}$, and hold at $220^{\circ} \mathrm{C}$ for $0.75 \mathrm{~min}$ after ramping at $2^{\circ} \mathrm{C} \mathrm{min}^{-1}$. The injector temperature increased from 150 to $250^{\circ} \mathrm{C}$ at $200^{\circ} \mathrm{C} \mathrm{min}{ }^{-1}$. Peaks were detected by flame ionization with the detector held at $260^{\circ} \mathrm{C}$. Fatty acids peaks were integrated using Varian Star chromatography software (Version 4.02) and identification was made with reference to known standards (PUFA 1 and 37 Component FAME Mix, Supelco). Based on whole-body lipid concentrations, the qualitative (proportional) measures of fatty acid content were then used to calculate the concentrations of each identified fatty acid ( $\mathrm{mg} \mathrm{g}^{-1}$ wet mass).

Statistical analyses. All statistical analyses were performed with Minitab Version 13.1. The level of significance for all tests was $\alpha=0.05$. Data are presented as means \pm SE. All data were tested for the assumptions of the statistical tests used (normality, homogeneity and independence of residuals; Sokal \& Rohlf 1995).

We recognize the potentially confounding factor of tank effects on our treatments and, for behavioral observations and growth measurements, we performed tests for tank effects by performing a 2-way ANCOVA (within each predator-temperature treatment combination) with the factors of tank and time (the duration of the experiment in weeks was used as a covariate). In all cases, the effects of the rearing tanks and the time $\times$ tank interactions were insignificant ( $p>0.60$ in all cases). Because of the high number of observations performed for each tank during this study, this method is a highly sensitive test for tank effects. For this reason, the effects of rearing tanks were not included in subsequent analysis.

For behavioral observations, 3-way ANCOVA was initially performed for each temperature using the General Linear Model (GLM) with the factors of predator treatment, tank grid section and fish age (in weeks; used as a covariate). The covariate of age is indistinguishable from time in the experiment, and so this analysis accounts for the repeated nature of our sampling (in a repeated measures analysis, time can be used as a categorical variable or a covariate). It was found that the tank grid section (proximity to the predator) had no significant affect, and so the data from all sections were pooled and a revised 2-way ANCOVA was performed using the GLM for each experimental temperature. The effects of age, predators, and the interaction of these 2 factors were of interest in the present study. The interaction term was significant in some cases and prevented the interpretation of the lower-order terms (see Table 2). To allow for further interpretation, unpaired $t$-tests were performed for each week to compare differences in the response variables between the treatments.

For changes in standard length over time, a 2-way ANCOVA was performed within each temperature treatment with the factors of predator treatment and 
fish age (used as a covariate) to examine the effects of predator presence on growth rates (by comparing the slopes of the regression equations). For final wet weights, hepatosomatic indices, and lipid class and fatty acid profiles, a 2-way ANOVA was performed (using the factors of predator treatment and temperature), followed by a post-hoc Tukey-Kramer test to examine differences across all temperature-predator treatment combinations.

\section{RESULTS}

\section{Behavioral observations}

The main form of locomotion in the young ocean pout was to 'crawl' along the bottom of the tank using their pectoral fins for support. Only rarely were individuals observed to leave the bottom and swim in the water column. Over the course of the experiment, the number of crawls performed by individuals during the observation periods increased significantly, particularly for the pout at $8^{\circ} \mathrm{C}$ (Fig. 2, Table 2). At both temperatures, this rate of increase was greater for pout reared in the absence of predators. These pout had significantly more crawls by the middle and late stages of the study (there were significant age-predator interactions indicating that the slopes between the predator and control treatments were different within each temperature).

At both temperatures, pout decreased foraging activity while visually exposed to the predators (fewer orients and lunges; Fig. 2, Table 2), although the tendency to reduce foraging was not influenced by proximity to the predator (as indicated by the analysis of data from the different grid sections of the prey chamber). The frequency of orients increased with increasing age at both temperatures, but at $8^{\circ} \mathrm{C}$, the rate of this increase over time was lower in the predator treatment compared to the control (there was a significant agepredator interaction). Regardless of predator treatment, the frequency of lunges showed a significant increase with increasing age at $8^{\circ} \mathrm{C}$, but did not increase at $3^{\circ} \mathrm{C}$. On average, for pout at $3^{\circ} \mathrm{C}$, the number of orients and lunges in the predator treatment were both reduced to approximately $63 \%$ of the control frequency. At $8^{\circ} \mathrm{C}$, the mean number of orients in the presence of predators was reduced to $67 \%$ of control rates, while the frequency of lunges was reduced to $73 \%$ of the control rate.

\section{Growth}

Within the $3^{\circ} \mathrm{C}$ treatments, pout raised without predators had a significantly higher wet mass at the end of the experiment (control: $490.60 \pm 6.64 \mathrm{mg}_{\text {; }}$ predator treatment: $426.61 \pm 13.75 \mathrm{mg}_{i}$ ANOVA, Tukey-Kramer, $\mathrm{p}=0.0003)$. In addition, they had a significantly higher growth rate in terms of standard length (Fig. 3; control: $1.40 \pm 0.05 \mathrm{~mm} \mathrm{wk}^{-1}$; predator treatment: $1.06 \pm 0.05 \mathrm{~mm} \mathrm{wk}^{-1}$; ANCOVA, $\mathrm{p}<0.0001$ ). Pout in the $8^{\circ} \mathrm{C}$ treatments did not show significant differences in final wet mass (control: $568.20 \pm 13.67 \mathrm{mg}$; predator treatment: $544.59 \pm 26.84 \mathrm{mg}_{i}$ ANOVA, Tukey-Kramer, $\mathrm{p}=0.44$ ), and although the growth rate of the predator-exposed pout was decreased (Fig. 3;

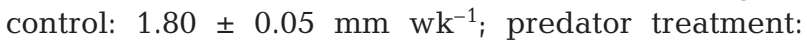
$\left.1.60 \pm 0.09 \mathrm{~mm} \mathrm{wk}^{-1}\right)$, this difference was not significant (ANCOVA, $\mathrm{p}=0.061, F=3.54$ ).
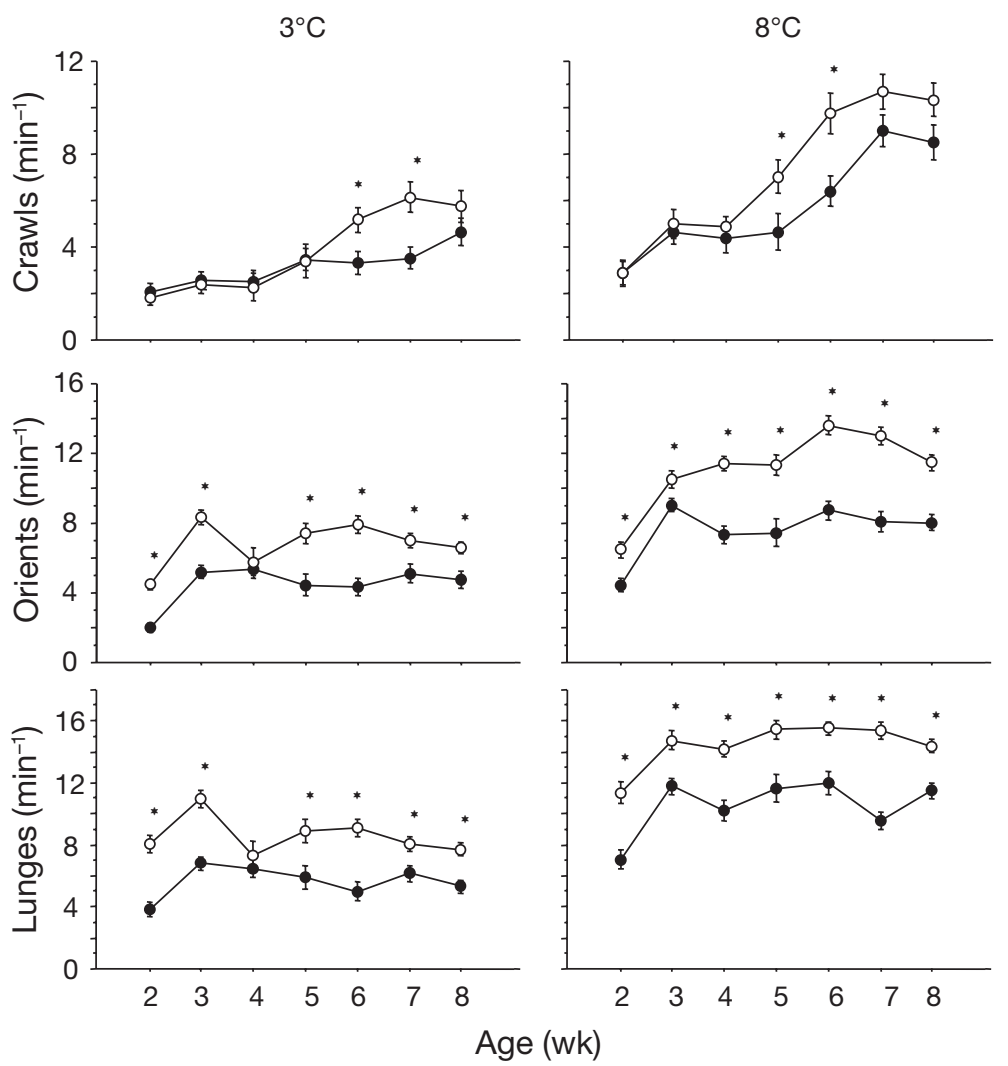

Fig. 2. Macrozoarces americanus. Frequencies (mean $\pm \mathrm{SE}$ ) of behavioral modal action patterns for young ocean pout reared at $3^{\circ}$ or $8^{\circ} \mathrm{C}$. $\bullet$ : individuals observed during visual exposure to predators (juvenile Atlantic cod Gadus morhua); O: control individuals not exposed to predators. ${ }^{*}$ Significant difference between predator treatment and control $(\mathrm{p}<0.05)$ 
Table 2. Macrozoarces americanus. General linear model results for observations of modal action patterns (MAPs) for young ocean pout reared with frequent predatory exposures compared to a control, at 3 and $8^{\circ} \mathrm{C}$. Linear regression equations calculated using age of pout (in weeks, a) as covariate. Mean value for each MAP (counts $\min ^{-1}$ ) represents overall mean over entire experimental period for each treatment. *Significant difference $(\mathrm{p}<0.05)$. ^lower-order terms cannot be evaluated independently because interaction term is significant. $\mathrm{n}$ is higher for $8^{\circ} \mathrm{C}$ treatments because at this temperature there were more instances of pout moving into the open when the observation had begun (while the individual was hiding). Only observations of individuals in the open were used in this study

\begin{tabular}{|c|c|c|c|c|c|c|}
\hline MAP & Treatment & Regression & $\begin{array}{l}\text { Mean }( \pm \mathrm{SE}) \\
\left(\text { counts } \mathrm{min}^{-1}\right)\end{array}$ & Term & $\mathrm{p}$ & $F$ \\
\hline \multicolumn{7}{|c|}{$3^{\circ} \mathrm{C}(\mathrm{n}=546)$} \\
\hline \multirow[t]{3}{*}{ Crawl } & Control & $Y=0.76+0.80 a$ & $3.80 \pm 0.23$ & Age & $<0.001^{* \wedge}$ & 77.50 \\
\hline & Predator & $Y=1.65+0.33 a$ & $3.15 \pm 0.19$ & Predator & 0.121 & 2.29 \\
\hline & & & & Age $\times$ Predator & $0.002^{*}$ & 9.97 \\
\hline \multirow[t]{3}{*}{ Orient } & Control & $Y=6.18+0.20 a$ & $6.95 \pm 0.20$ & Age & $<0.001^{*}$ & 11.42 \\
\hline & Predator & $Y=3.47+0.24 a$ & $4.43 \pm 0.18$ & Predator & $<0.001^{*}$ & 21.90 \\
\hline & & & & Age $\times$ Predator & 0.759 & 0.09 \\
\hline \multirow[t]{3}{*}{ Lunge } & Control & $Y=9.70-0.22 a$ & $8.86 \pm 0.24$ & Age & 0.276 & 1.19 \\
\hline & Predator & $Y=5.41-0.05 a$ & $5.62 \pm 0.21$ & Predator & $<0.001^{*}$ & 39.89 \\
\hline & & & & Age $\times$ Predator & 0.077 & 3.13 \\
\hline \multicolumn{7}{|c|}{$8^{\circ} \mathrm{C}(\mathrm{n}=752)$} \\
\hline \multirow[t]{3}{*}{ Crawl } & Control & $Y=1.76+1.37 a$ & $7.45 \pm 0.29$ & Age & $<0.001^{* \wedge}$ & 167.58 \\
\hline & Predator & $Y=2.08+0.96 a$ & $5.78 \pm 0.27$ & Predator & 0.689 & 0.16 \\
\hline & & & & Age $\times$ Predator & $0.023^{*}$ & 5.16 \\
\hline \multirow{3}{*}{ Orient } & Control & $Y=8.54+0.67 a$ & $11.34 \pm 0.20$ & Age & $<0.001^{* \wedge}$ & 48.44 \\
\hline & Predator & $Y=6.48+0.31 a$ & $7.66 \pm 0.20$ & Predator & $<0.001^{* \wedge}$ & 10.52 \\
\hline & & & & Age $\times$ Predator & $0.023^{*}$ & 6.80 \\
\hline \multirow[t]{3}{*}{ Lunge } & Control & $Y=13.2+0.32 a$ & $14.55 \pm 0.21$ & Age & $<0.001^{*}$ & 17.23 \\
\hline & Predator & $Y=9.31+0.33 a$ & $10.57 \pm 0.25$ & Predator & $<0.001^{*}$ & 30.51 \\
\hline & & & & Age $\times$ Predator & 0.988 & 0.00 \\
\hline
\end{tabular}

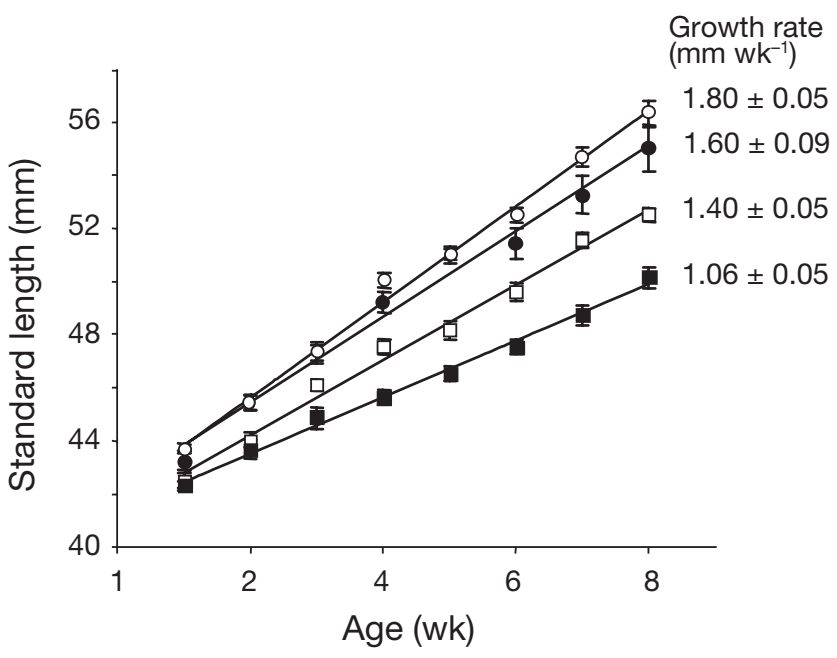

Fig. 3. Macrozoarces americanus. Increases in standard length (SL) with age $(a)$ in young ocean pout reared at $3^{\circ} \mathrm{C}(\mathbf{\square}$, ㅁ) or $8^{\circ} \mathrm{C}(\bullet, 0)$. Filled symbols represent treatments in which ocean pout were visually exposed to predators (juvenile Atlantic cod Gadus morhua); open symbols represent control treatments (no exposure to predators). Regression equations are as follows: control at $3^{\circ} \mathrm{C}$ : $\mathrm{SL}=41.42+1.41 \mathrm{a}$; predator treatment at $3^{\circ} \mathrm{C}: \mathrm{SL}=41.38+1.06 a$; control at $8^{\circ} \mathrm{C}: \mathrm{SL}=$ $42.09+1.80 a$; predator treatment at $8^{\circ} \mathrm{C}: \mathrm{SL}=42.34+1.60 a$. Growth rates (regression slopes) are shown beside each regression line $( \pm \mathrm{SE})$, and were significantly different between predator treatment and control at $3^{\circ} \mathrm{C}$ (ANCOVA, $\mathrm{p}<0.0001$, $F=23.71)$, but not at $8^{\circ} \mathrm{C}(\mathrm{ANCOVA}, \mathrm{p}=0.061, F=3.54)$. Data points are mean $\pm \mathrm{SE}_{i} \mathrm{n}=10$ for each data point

\section{Lipid classes}

Initial lipid class and fatty acid levels (from samples collected at the beginning of the study) are listed in Table 3. By the end of the study, individuals reared in the presence of predators at $3^{\circ} \mathrm{C}$ had hepatosomatic indices (HSI) that were about $45 \%$ lower than pout that were not exposed to predators (Table 4). Furthermore, pout exposed to predators at $3^{\circ} \mathrm{C}$ had $30 \%$ less whole-body lipid content by the end of the study (Table 4). At $8^{\circ} \mathrm{C}$, there were no significant differences in HSI or whole-body lipid content. However, the HSI and whole-body lipid levels in either treatment at $8^{\circ} \mathrm{C}$ were similar to those in the predator treatment at $3^{\circ} \mathrm{C}$.

The most abundant lipid classes found in our analysis were phospholipids (PL), sterols (ST), and triacylglycerols (TAG). At $3^{\circ} \mathrm{C}$, pout exposed to predators had about $27 \%$ less PL at the end of the study and $36 \%$ less TAG compared to pout that were not exposed to predators (Fig. 4). At $8^{\circ} \mathrm{C}$, however, there were no significant differences between the predator treatments for either PL or TAG. Overall, pout at $8^{\circ} \mathrm{C}$ had final TAG concentrations that were significantly lower compared to pout at $3^{\circ} \mathrm{C}$, regardless of predator treatment. Rearing temperature did not have a significant effect on PL. Neither predators nor temperature had a significant affect on ST concentrations. 
Table 3. Macrozoarces americanus. Mean $( \pm \mathrm{SE})$ initial lipid and fatty acid profiles for ocean pout used in this study. Samples were taken $1 \mathrm{wk}$ post-hatch, after pout in the $8^{\circ} \mathrm{C}$ treatments were allowed to acclimate to this temperature. Only essential fatty acids (AA, EPA, DHA), and fatty acids which were present in abundances $>5 \%$ of total identified fatty acids are shown. $\mathrm{n}=8$ for each temperature

\begin{tabular}{|c|c|c|}
\hline & $3^{\circ} \mathrm{C}$ & $8^{\circ} \mathrm{C}$ \\
\hline Total lipids (mg g ${ }^{-1}$ wet mass) & $35.23 \pm 2.79$ & $38.52 \pm 3.46$ \\
\hline \multicolumn{3}{|l|}{ Lipid classes ( $\mathrm{mg} \mathrm{g} \mathrm{g}^{-1}$ wet mass) } \\
\hline Phosphlipids & $13.97 \pm 2.00$ & $15.47 \pm 1.21$ \\
\hline Sterols & $2.95 \pm 0.27$ & $3.42 \pm 0.19$ \\
\hline Triacylglycerols & $14.34 \pm 0.93$ & $16.3 \pm 2.06$ \\
\hline \multicolumn{3}{|l|}{ Fatty acids (mg g ${ }^{-1}$ wet mass) } \\
\hline $16: 0$ & $3.60 \pm 0.33$ & $3.85 \pm 0.35$ \\
\hline $16: 1 \omega 7$ & $1.89 \pm 0.30$ & $0.90 \pm 0.26$ \\
\hline $18: 0$ & $0.87 \pm 0.08$ & $0.93 \pm 0.09$ \\
\hline $18: 1 \omega 9$ & $4.52 \pm 0.44$ & $4.70 \pm 0.30$ \\
\hline $18: 1 \omega 7$ & $1.34 \pm 0.27$ & $1.28 \pm 0.06$ \\
\hline $18: 3 \omega 3$ & $0.15 \pm 0.04$ & $0.21 \pm 0.45$ \\
\hline $20: 4 \omega 6$ (AA) & $0.46 \pm 0.10$ & $0.51 \pm 0.09$ \\
\hline $20: 5 \omega 3$ (EPA) & $4.51 \pm 0.60$ & $5.02 \pm 0.72$ \\
\hline 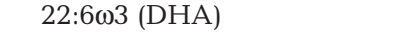 & $4.33 \pm 0.94$ & $6.26 \pm 0.96$ \\
\hline
\end{tabular}

\section{Fatty acids}

Initial fatty acid profiles (from samples collected at the beginning of the study) are listed in Table 3. By the end of the study, individuals exposed to predators at $3^{\circ} \mathrm{C}$ had lower levels of most identified fatty acids compared to pout not exposed to predators at the same temperature (Fig. 5). This includes significant decreases in the essential fatty acids arachidonic acid (AA) and eicosapentaenoic acid (EPA), although there was no difference in the levels of docosahexaenoic acid (DHA) between the predator treatments at this temperature. At $8^{\circ} \mathrm{C}$, there were no significant differences observed between the predator treatments for final levels of the identified fatty acids (including AA, EPA and DHA; Fig. 5). Regardless of predator treatment, pout reared at $8^{\circ} \mathrm{C}$ had final levels of most fatty acids that were similar to those of pout raised with predators at $3^{\circ} \mathrm{C}$.

Table 4. Macrozoarces americanus. Final hepatosomatic indices and wholebody lipid levels for young ocean pout reared in presence of frequent predation threat compared to control group ( $\mathrm{n}=14$ per treatment). Experiment was performed at 3 and $8^{\circ} \mathrm{C}$. Significant differences within each variable between predator-temperature combinations are indicated by different superscripted letters (ANOVA, Tukey-Kramer, $\mathrm{p}<0.05$ ). Data are mean $\pm \mathrm{SE}$

\begin{tabular}{|c|c|c|c|c|}
\hline & \multicolumn{2}{|c|}{$3^{\circ} \mathrm{C}-$} & \multicolumn{2}{|c|}{$8^{\circ} \mathrm{C}-$} \\
\hline & Control & Predator & Control & Predator \\
\hline Hepatosomatic index & $3.5 \pm 0.2^{\mathrm{a}}$ & $1.9 \pm 0.1^{b}$ & $2.2 \pm 0.1^{b}$ & $2.3 \pm 0.2^{b}$ \\
\hline Whole-body lipid $\left(\mathrm{mg} \mathrm{g}^{-1}\right)$ & $34.4 \pm 3.2^{\mathrm{a}}$ & $24.8 \pm 2.8^{\mathrm{b}}$ & $20.4 \pm 0.9^{b}$ & $22.6 \pm 1.5^{\mathrm{b}}$ \\
\hline
\end{tabular}

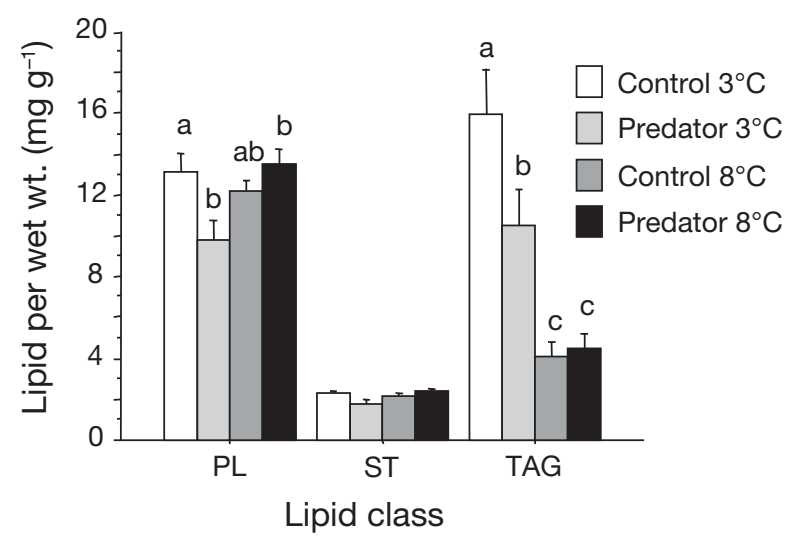

Fig. 4. Macrozoarces americanus. Final whole-body concentrations (mean $\pm \mathrm{SE}$ ) of phospholipids (PL), sterols (ST), and triacylglcerols (TAG) for young ocean pout reared at 3 or $8^{\circ} \mathrm{C}$, with and without presence of predators. In predator treatments, ocean pout were visually exposed to predators (juvenile Atlantic cod Gadus morhua), while in controls they were not. Significant differences between predator and temperature combinations are indicated by different letters (ANOVA, Tukey-Kramer, $\mathrm{p}<0.05, \mathrm{n}=10$ for each bar). There were no significant differences found across treatments for ST

\section{DISCUSSION}

Despite the potentially significant consequences of threat-sensitive foraging for individual growth and survival, there have been few studies that examine the energetic cost of reduced foraging rates due to predatory exposure. To our knowledge, this is the first study to examine the costs of threat-sensitive foraging in terms of growth and energy storage in newly hatched fishes.

To test the hypotheses of the present study, our aim was to cause frequent, prolonged interruptions to regular foraging behavior. One concern prior to this study was that the fish in the predator treatments would habituate to the presence of the predators and reduce any threat-sensitive foraging response (during the $6 \mathrm{~h}$ exposure and also over the course of the study). However, we found no evidence of habituation over the course of the experiments, as there were always differences in foraging activity between the predator treatments and the control tanks, and counts of MAPs in the predator treatments did not show increases over time. It should be noted that at the end of the $6 \mathrm{~h}$ predatory exposure, most pout in the predator treatments were either hiding in the provided cover, or had moved to the end of the tanks furthest from the predator chamber (pout in the control treatment were evenly distributed 


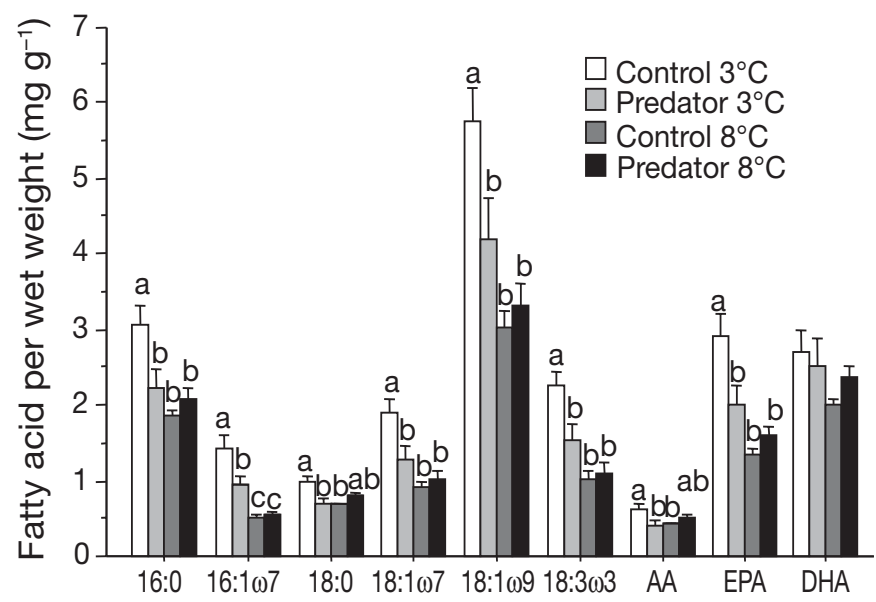

Fatty acid

Fig. 5. Macrozoarces americanus. Final fatty acid profiles (means $\pm \mathrm{SE}$ ) for young ocean pout reared at 3 or $8^{\circ} \mathrm{C}$, with and without presence of predators. In predator treatments, ocean pout were visually exposed to predators (juvenile Atlantic cod Gadus morhua), while in controls they were not. Only essential fatty acids (arachidonic acid, AA; eicosapentaenoic acid, EPA; and docosahexaenoic acid, DHA), and fatty acids which were present in abundances $>5 \%$ of the total identified fatty acids are shown. Significant differences between predator and temperature combinations are indicated by different letters (ANOVA, Tukey-Kramer, $\mathrm{p}<0.05, \mathrm{n}=10$ for each bar). Therewere no significant differences across treatments for DHA

throughout the aquaria). This would suggest that the individuals were still responding to the predators, since they continued to be vigilant after the $6 \mathrm{~h}$ of exposure.

\section{Behavioral observations}

When visually exposed to the predators, the young ocean pout did not appear to display the freezing or predator inspection behavior that is commonly observed in many species of teleost fishes (Williams \& Brown 1991). However, these behaviors may not be obvious in the young ocean pout because they do not actively swim in the water column. Individuals in control and predator treatments remained in contact with the tank bottom almost constantly, and moved only occasionally with short forward bursts (crawls). As such, the frequency of crawls may be used as an index of activity in the young ocean pout. At both experimental temperatures, pout in the control group began to show a higher frequency of crawls after 3 to 4 wk compared to pout in the predator treatment (until Week 7 at $3^{\circ} \mathrm{C}$ and Week 6 at $8^{\circ} \mathrm{C}$ ). This decreased level of activity in the presence of the predatory threat probably makes individuals less obvious to predators, and in this regard is analogous to the freezing behavior observed for actively swimming fishes. Many of the crawls that were made while in the presence of the predators were attempts to gradually move away from predator or move into the provided cover. 'Fleeing' by rapidly swimming away from the predator chamber was occasionally observed in response to sudden movements by the predators.

At both temperatures, pout showed reduced numbers of orients and lunges to capture Artemia sp. while in the presence of predators. It is well known that fishes will decrease foraging while under a perceived threat of predation, and our observations are in agreement with previous studies (e.g. Helfman 1989, Williams \& Brown 1991, Bishop \& Brown 1992, Engstrom-Ost \& Lehtiniemi 2004). The decreases in movement associated with foraging are thought to make the prey individuals more difficult for the predators to detect, and decreased rates of foraging may also allow the prey to be more vigilant to the behavior of the predator (Godin \& Smith 1988). Indeed, it has been shown that even very young fishes can assess the level of predatory threat present, and then make the appropriate foraging decision (Williams \& Brown 1991, Bishop \& Brown 1992, Leader 1994, Engstrom-Ost \& Lehtiniemi 2004). The ocean pout of the present study displayed threat-sensitive foraging $1 \mathrm{wk}$ post-hatch (as soon as the experiment was initiated). This is in contrast to larval Atlantic cod and the threespine stickleback Gasterosteus aculeatus, which are unresponsive to the presence of predators during the first few weeks post-hatch (Bishop \& Brown 1992, Leader 1994). This discrepancy is likely to be due to the fact that ocean pout are relatively large and well developed at hatch, and possess sensory capabilities that allow them to detect the presence of predators from a very early age. In the present study, the fact that the magnitude of the response to the predators was not dependent on proximity to the predator (within the confines of the experimental tanks) seems to support this theory. In the previous studies examining species that have less developed larvae, it has been observed that the larvae will only respond to predators that visually exposed within a few centimeters (Bishop \& Brown 1992, Leader 1994).

It was thought that a higher rearing temperature might have necessitated continued foraging at $8^{\circ} \mathrm{C}$, even while under the threat of predation. Fishes have been observed to make state-dependent foraging decisions, with 'hungry' individuals engaging in more risky behavior (Dill \& Frazer 1984, Gotceitas \& Godin 1991, Godin \& Crossman 1994). Presumably, increased metabolic rate in the pout at $8^{\circ} \mathrm{C}$ would have resulted in increased levels of hunger and motivation to feed. Also, the pout at $8^{\circ} \mathrm{C}$ appeared to expend more energy through activity, as measured by the frequency of 
crawls. It was surprising then, that pout exposed to predators at $8^{\circ} \mathrm{C}$ showed large reductions in foraging activity that were similar in magnitude to those observed at $3^{\circ} \mathrm{C}$. Similarly, Williams \& Brown (1991) failed to report a 'hunger' response when they observed no relation between the Artemia sp. ration fed to larval lumpfish Cyclopterus lumpus and their willingness to engage in risky behavior. These authors suggested that the lowest Artemia sp. ration in their study was probably still too high to elicit this hunger response. A similar scenario may have occurred in the present study. There was no mortality observed in this study, which suggests that although the $8^{\circ} \mathrm{C}$ pout may have been 'energetically stressed' (see discussion on lipid levels below), they were not starved to the point where feeding was prioritized over the more immediate threat of predatory presence.

\section{Growth}

The consequences of the reduced foraging activity were most serious for the pout reared at $3^{\circ} \mathrm{C}$. At this temperature, pout exposed to predators had reduced length-specific growth rates compared to pout in the control treatment, and had a lower wet mass at the end of the experiment. Interestingly, the differences in growth rate at $8^{\circ} \mathrm{C}$ were not statistically significant, despite the reduced foraging that was observed in the presence of predators at this temperature. The exact reason for this discrepancy is not known but potential explanations are discussed later. Nonetheless, our findings at $3^{\circ} \mathrm{C}$ suggest that it is possible for the costs of threat-sensitive foraging to accumulate and affect growth rates over time. Previous studies have also found that the presence of predators can have profound indirect effects on prey fish populations, including reductions in growth rate (Fraser \& Gilliam 1992, Tonn et al. 1992, Diehl \& Eklov 1995, Persson \& Eklov 1995). However, in these studies, the reductions in growth were the result of prey switching to habitats that were less energetically profitable (either due to decreased prey abundance or quality, or through increased competition due to high population densities). In contrast, the differences in growth found in the present study appear to be attributable to the reduced foraging rates caused by the frequent predatory exposure. The limited energy stores of young fishes, coupled with high metabolic rates associated with small body size, probably make reductions in feeding especially costly during the early life stages. Also, due to their small size, young fishes in the wild will have many potential predators and so their frequency of predatory encounters will be relatively high, even while occupying 'refuge' areas such as habitats with vegetation. Although it is important to understand the effects of predator-induced habitat restriction on the size-structure of prey populations, it is also necessary to examine the costs of reduced foraging activity when encounters with predators occur.

Fast growth is critical during the early life-stages of fishes, as size-dependent predation is a main source of mortality at this time (Bailey \& Houde 1989). Individuals that grow slowly will be at a disadvantage because they will spend more time as a potential food source for predators (Fuiman \& Magurran 1994). It should be noted that compared to many marine fishes, ocean pout are relatively large at hatch and do not possess a distinct 'larval' stage (Methven \& Brown 1991). Therefore, trends observed with young ocean pout are probably most transferable to the early juvenile stage of species that hatch as larvae. The costs of threat-sensitive foraging may be even greater for larvae, however, since slowed growth may be accompanied by disruptions to normal development. Although no mortality was observed in the present study, larval fishes can suffer severe consequences if nutritional requirements are not met at key stages of ontogeny, and could experience increased rates of indirect mortality if frequently exposed to predation threat during this delicate life-stage.

\section{Lipid classes}

Lipid analyses were performed to examine how energy storage is affected by threat-sensitive foraging. Pout exposed to predators at $3^{\circ} \mathrm{C}$ had significantly reduced final whole-body lipid content compared to the control group. Furthermore, pout in the predator treatment had smaller livers (as measured by HSI), an organ that is a primary storage site for lipids in young fishes. Of the lipid classes analyzed, the most pronounced effects of predator presence were observed in the levels of PL and TAG. Both types of lipid showed large reductions in pout exposed to predators at $3^{\circ} \mathrm{C}$. PL are a main constituent of cellular membranes and are important as young fishes grow and develop new tissue. TAG are mainly used for energy storage, and so it is clear that the control group were better able to maintain energy reserves compared to pout in the predator treatment. The potential impacts of this reduction in energy reserves are not known, but it is generally accepted that lipids are an important metabolic fuel in young fishes (Sargent 1995). TAG reserves are catabolized when feeding rates are not sufficient to support the metabolic demands of individuals, and TAG content has been shown to have a positive correlation with physiological condition in fish larvae (Fraser 1989). Furthermore, the juveniles of many 
fish species reduce foraging during the colder winter months and must accumulate lipid reserves prior to this over-wintering period for survival (Post \& Evans 1989). It is not known if young ocean pout decrease foraging during the winter, but this would be another important consequence of decreases in lipid levels due to frequent predatory encounters.

Similar to the lack of growth differences between the predator and control treatments at $8^{\circ} \mathrm{C}$, there were also no differences in HSI, whole-body lipid levels, or PL and TAG at this temperature. These results are surprising, but there are at least 2 lines of reasoning that may explain these findings. First, compared to pout at $3^{\circ} \mathrm{C}$, individuals exposed to predators at $8^{\circ} \mathrm{C}$ may have been better able to compensate for lost feeding opportunities once the exposure period had concluded, thus reducing differences in growth and lipid storage. Foraging behavior was not quantified after the period of predatory exposure, but this scenario may have been possible since, in general, pout in the $8^{\circ} \mathrm{C}$ treatment were more active than pout at $3^{\circ} \mathrm{C}$ and had higher rates of feeding (Table 2; mean frequencies for crawls, orients and lunges). Second, the effects of temperature on growth and metabolism at $8^{\circ} \mathrm{C}$ may have overwhelmed our ability to observe any effects of predatory exposure at this temperature. For example, pout at $8^{\circ} \mathrm{C}$ may allocate most ingested energy toward activity, growth and maintenance, and very little to energy storage - thus causing a reduced ability to detect differences in lipid levels. Supporting this view, TAG levels in both treatments at $8^{\circ} \mathrm{C}$ were greatly reduced compared to either treatment at $3^{\circ} \mathrm{C}$, despite the fact that overall, pout at $8^{\circ} \mathrm{C}$ foraged nearly twice as much as pout at $3^{\circ} \mathrm{C}$ (Table 2 , mean counts for lunges). Furthermore, even without additional stressors, young fishes are believed to have a diminished factorial aerobic scope that may limit growth rates (factorial aerobic scope = maximal metabolic rate/routine metabolic rate; Post \& Lee 1996, Blier \& Pelletier 1997). An increased energetic cost of maintenance at higher temperatures could further decrease the metabolic scope available for growth if maximal aerobic capabilities do not increase with increasing temperature as well. In this regard, the routine metabolic rate of young ocean pout has been found to increase substantially with increasing temperature (S. S. Killen, J. A. Brown, A. K. Gamperl unpubl. data). The change in maximal aerobic metabolism with temperature in young ocean pout is not known, but aerobic scope in adult Norwegian eelpout Zoarces viviparous decreases considerably with increases in temperature, and growth rate declines at temperatures above their optimum (Zakhartsev et al. 2003). Based on this evidence, we speculate that growth rates of the pout at $8^{\circ} \mathrm{C}$ may have been close to the physiological maximum, even during the relatively low foraging rates that were observed for the pout exposed to predators. This scenario could make it difficult to observe any reductions in growth at $8^{\circ} \mathrm{C}$. Additional research into the thermal physiology of young ocean pout is needed to resolve these issues.

Regardless of the mechanisms responsible for the unexpected results at $8^{\circ} \mathrm{C}$, the fact that different conclusions were reached when the same experiment was performed at 2 different temperatures points to the extreme importance of temperature selection in experiments studying foraging and energy acquisition in ectotherms. This is particularly true for young or larval fishes, for which relatively little is known about the effects of environmental conditions on metabolism. In the wild, young ocean pout can be found at both of the water temperatures used in this study, and so it would have been justifiable to perform the experiment at only one of these temperatures. However, if the study had been performed at only $8^{\circ} \mathrm{C}$, we would have found no accumulated cost associated with threat-sensitive foraging. We therefore recommend that studies examining the costs of threat-sensitive foraging in fishes be performed at multiple temperatures (within the range that is normally experienced in the wild).

\section{Fatty acids}

To better understand the biochemical changes in young fishes exposed to frequent predation threat, we examined the fatty acid compositions of pout from the different treatments. At $3^{\circ} \mathrm{C}$, the predator treatment had lower levels of most fatty acids identified in our analyses. For example, large differences were observed for various saturated and monounsaturated fatty acids that are readily metabolized for energy. Once again, however, there were no differences between the treatments at $8^{\circ} \mathrm{C}$. The $8^{\circ} \mathrm{C}$ pout in both treatments also had levels of most fatty acids that were similar to the $3^{\circ} \mathrm{C}$ pout from the predator treatment, providing further evidence that the $8^{\circ} \mathrm{C}$ had limited energy stores.

Adequate lipid nutrition is crucial for young marine fishes not only in providing energy, but to also in supplying certain essential highly unsaturated fatty acids (HUFAs) that are important for regular development.

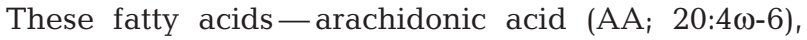
eicosapentaenoic acid (EPA; 20:5 $\omega$-3), and docosahexaenoic acid $\left(\mathrm{DHA}_{;} 22: 6 \omega-3\right)$ - must be obtained from the diet because they cannot be synthesized by marine fishes (Sargent et al. 1999, Bell et al. 2003). Deficiencies of essential HUFAs have been found to cause reductions in growth, survival and resistance to stress in larval fishes (Watanabe 1993, Bell et al. 2003). Pout exposed to predators at $3{ }^{\circ} \mathrm{C}$ showed decreased levels of AA and EPA compared to the control, and 
so it appears that frequent reduced foraging due to predatory threat can affect the intake of essential fatty acids. Although levels of DHA were not different among any of the treatments, differences resulting from decreased foraging might be difficult to distinguish since starved larvae are known to preferentially conserve DHA (Rainuzzo et al. 1997). Deficiencies of essential HUFAs may have significant consequences during the early life-stages of fishes, especially for the development of neural tissue and visual systems (Tocher 2003). Such effects would be very serious for young fishes, since reduced sensory capabilities may lead to an inability to avoid predation or to capture prey themselves. For example, larval herring deprived of DHA have a reduced ability to capture prey at low light intensities (Bell et al. 1995). Reduced concentrations of essential HUFAs could also alter behaviors associated with neuroendocrine function, but this area requires further study.

\section{CONCLUSIONS}

This study has shown that frequent interruptions to foraging due to predation threat can cause reduced growth rates in young marine fishes. It is also clear that water temperature can have a profound effect on experiments examining the costs of reduced foraging under predation threat. Furthermore, both predation and water temperature can have a direct impact on the lipid composition and energy storage abilities of young fish. If energy is viewed as a currency in the trade-off between foraging and predator avoidance, the individuals exposed to predators at the colder temperature in this study were clearly suffering a heavy cost due to frequent foraging disruptions. Future studies should address how such reductions in growth and lipid content may affect competitive ability or survival under adverse environmental conditions.

Acknowledgements. This work was supported by the Memorial University of Newfoundland and the Natural Sciences and Engineering Research Council of Canada. We thank the technical services division of the Ocean Sciences Centre, the staff of the Aquaculture Research Development Facility (ARDF) for the rearing of Artemia sp. used in this study, and P. Sargent, R. Boland and B. MacDonald for collection of the pout eggs. We also thank Dr. D. C. Schneider for his assistance with the statistical analysis, and 4 anonymous reviewers who greatly improved the quality of this manuscript. Finally, we thank Dr. C. C. Parrish for his comments on earlier versions of this manuscript and for allowing us the use of his laboratory, and V. French for her technical assistance with the lipid and fatty acid analysis. This study was conducted in accordance with the guidelines of the Canadian Council on Animal Care and the Animal Care Committee of the Memorial University of Newfoundland.

\section{LITERATURE CITED}

Abrahams MV, Dill LM (1989) A determination of the energetic equivalence of the risk of predation. Ecology 70:99-1007

Altmann J (1974) Observational study of behaviour: sampling methods. Behaviour 49:227-265

Bailey K M, Houde ED (1989) Predation on eggs and larvae of marine fishes and the recruitment problem. Adv Mar Biol 25:1-89

Ball SL, Baker RL (1996) Predator-induced life history changes: antipredator behavior costs facultative life history shifts? Ecology 77:1116-1124

Barlow GW (1968) Ethological units of behaviour. In: Ingle DJ (ed) The central nervous system and fish behaviour. University of Chicago Press, Chicago, IL

Bell JG, McEvoy LA, Estevez A, Shields RJ, Sarent JR (2003) Optimising lipid nutrition in first-feeding flatfish larvae. Aquaculture 227:211-220

Bell MV, Batty RS, Dick JR, Fretwell K, Navarro JC, Sargent JR (1995) Dietary deficiency of docosahexaenoic acid impairs vision at low light intensities in juvenile herring (Clupea harengus L.). Lipids 30:442-449

Bishop TD, Brown JA (1992) Threat-sensitive foraging by larval threespine sticklebacks (Gasterosteus aculeatus). Behav Ecol Sociobiol 31:133-138

Blier PU, Pelletier D (1997) Does aerobic capacity set a limit on fish growth rates? Rev Fish Sci 5:323-340

Copeman LA, Parrish CC, Brown JA, Harel M (2002) Effects of docosahexaenoic, eicosapentaenoic, and arachadonic acids on the early growth, survival, lipid composistion and pigmentation of yellowtail flounder (Limanda ferrunginea) a live food enrichment experiment. Aquaculture 210: 285-304

Diehl S, Eklov P (1995) Effects of piscivore-mediated habitat use on resources, diet, and growth of perch. Ecology 76: $1712-1726$

Dill LM, Fraser AGH (1984) Risk of predation and the feeding behavior of juvenile coho salmon (Onchorhynchus kisutch). Behav Ecol Sociobiol 16:65-71

Dixon SM, Baker RL (1988) Effects of size on predation risk, behavioural response to fish, and cost of reduced feeding in larval Ischnura verticalis (Coenagrionidae: Odonata). Oecologia 76:200-205

Engstrom-Ost J, Lehtiniemi M (2004) Threat-sensitive predator avoidance by pike larvae. J Fish Biol 65:251-261

Folch J, Lees M, Sloane-Stanley GH (1957) A simple method for the isolation and purification of total lipids from animal tissues. J Biol Chem 22:497-509

Fraser A (1989) Triacylglycerol content as a condition index for fish, bivalve, and crustacean larvae. Can J Fish Aquat Sci 46:1868-1873

Fraser DF, Gilliam JF (1992) Nonlethal impacts of predator invasion: facultative suppression of growth and reproduction. Ecology 73:959-970

Fuiman LA (1994) The interplay of ontogeny and scaling in the interactions of fish larvae and their predators. J Fish Biol 45 (Suppl A):55-79

Fuiman LA, Magurran AE (1994) Development of predator defences in fishes. Rev Fish Biol Fish 4:145-183

Godin JGJ, Crossman SL (1994) Hunger-dependent predator inspection and foraging behaviors in the threespine stickleback (Gasterosteus aculeatus) under predation risk. Behav Ecol Sociobiol 34:359-366

Godin JGJ, Smith SA (1988) A fitness cost of foraging in the guppy. Nature 333:69-71

Gotceitas V, Godin JGJ (1991) Foraging under the risk of predation in juvenile Atlantic salmon (Salmo salar L.): 
effects of social status and hunger. Behav Ecol Sociobiol 29:255-261

Helfman GS (1989) Threat-sensitive predator avoidance in damselfish-trumpetfish interactions. Behav Ecol Sociobiol 24:47-58

Houston AI, McNamara JM, Hutchinson JM (1993) General results concerning the trade-off between gaining energy and avoiding predation. Proc R Soc Ser B 341:375-397

Leader LL (1994) To feed or not to feed?: the ontogeny of foraging and predator avoidance trade-offs in larval cod (Gadus morhua). MS thesis, Memorial University of Newfoundland, St. John's

Leggett WC, Deblois E (1994) Recruitment in marine fishes is it regulated by starvation and predation in the egg and larval stages? Neth J Sea Res 32:119-134

Lima SL (1998a) Nonlethal effects in the ecology of predator-prey interactions. BioScience 48:25-34

Lima SL (1998b) Stress and decision making under the risk of predation: recent developments from behavioral, reproductive, and ecological perspectives. Adv Stud Behav 27: 215-290

Lima SL, Dill LM (1990) Behavioral decisions made under the risk of predation: a review and prospectus. Can J Zool 68: 619-640

Methven DM, Brown JA (1991) Time of hatching affects development, size, yolk volume, and mortality of newly hatched Macrozoarces americanus (Pisces: Zoarcidae). Can J Zool 69:2161-2167

Morrison WR, Smith LM (1964) Preparation of fatty acid methyl esters and dimethylacetals from lipids with boron fluoride methanol. J Lipid Res 5:600-608

Parrish CC (1998) Determination of total lipid, lipid classes, and fatty acids in aquatic samples. In: Arts MT, Wainman BC (eds) Lipids in freshwater ecosystems. Springer-Verlag, New York, p 4-12

Peacor SD, Werner EE (2000) Predator effects on an assemblage of consumers through induced changes in consumer foraging behavior. Ecology 81:1998-2010

Persson L, Eklov P (1995) Prey refuges affecting interactions between piscivorous perch and juvenile perch and roach. Ecology 76:70-81

Post JE, Evans DO (1989) Size-dependent overwinter mortality of young-of-the-year yellow perch (Perca flavescens) -

Editorial responsibility: Otto Kinne (Editor-in-Chief), Oldendorf/Luhe, Germany laboratory, in situ enclosure, and field experiments. Can J Fish Aquat Sci 46:1958-1968

Post JR, Lee JA (1996) Metabolic ontogeny of teleost fishes. Can J Fish Aquat Sci 53:910-923

Rainuzzo JR, Reitan KI, Olsen Y (1997) The significance of lipids at the early stages of marine fish: a review. Aquaculture 155:103-115

Sargent JR (1995) Origins and functions of lipids in fish eggs: nutritional implications. In: Bromage NR, Roberts RR (eds) Broodstock management and egg quality. Blackwell Science, Oxford

Sargent J, McEvoy L, Estevez A, Bell G, Bell M, Henderson J, Tocher D (1999) Lipid nutrition of marine fish during early development: current status and future directions. Aquaculture 179:217-229

Skajaa K, Ferno A, Folkvord A (2003) Swimming, feeding and predator avoidance in cod larvae (Gadus morhus L.): trade-offs between hunger and predation risk. In: Browman HI, Skiftesvik AB (eds) The big fish bang. Proceedings of the 26th Annual Larval Fish Conference. Institute of Marine Research, Bergen, p 105-121

Skelly DK (1992) Field evidence for a cost of behavioral antipredator response in a larval amphibian Ecology 73: 704-708

Sokal RR, Rohlf FJ (1995) Biometry. The principles and practice of statistics in biological research, 3rd edn. WH Freeman, New York

Tocher DR (2003) Metabolism and function of lipids and fatty acids in teleost fish. Rev Fish Sci 11:107-184

Tonn WM, Paszkowski CA, Holopainen IJ (1992) Piscivory and recruitment: mechanisms structuring prey populations in small lakes. Ecology 73:951-958

Watanabe T (1993) Importance of docosahexaenoic acid in marine larval fish. J World Aquacult Soc 24:152-161

Werner EE, Anholt BR (1996) Predator-induced behavioral indirect effects: consequences to competitive interactions in anuran larvae. Ecology 77:157-169

Williams PJ, Brown JA (1991) Developmental changes in foraging-predator avoidance trade-offs in larval lumpfish Cyclopterus lumpus. Mar Ecol Prog Ser 76:53-60

Zakhartsev MV, De Watcher B, Sartoris FJ, Portner HO, Blust R (2003) Thermal physiology of the common eelpout (Zoarces viviparus). J Comp Physiol B 173:365-378

Submitted: October 13, 2005; Accepted: February 10, 2006 Proofs received from author(s): August 18, 2006 